\title{
Research Overview on Training Progress for High School Teachers
}

\author{
Dao Thi Thu Hang \\ National Academy of Education Management, Vietnam \\ Corresponding author email: daothuhang070387@gmail.com
}

\begin{abstract}
Pedagogy training is a fundamental programme that should be conducted regularly, especially in the context of reforming the general Vietnam education recently. The research objective aims to classify the development process of training activities for high school teachers. The research methodology is based on the historical and comparative approaches to present the maturing process of teaching apprentices for the high school workforce. The research result reveals that although the training activities for high school teachers have been in many countries' consideration for a long time within the innovation of education and society, there is a shortage of in-depth studies for this topic as well as professional capacity building management in the Vietnamese teaching labour today.

Keywords---high school, management, research overview, teachers capabilities, training activities
\end{abstract}

\section{Introduction}

In many countries around the world, the teacher has been prioritized as a relatively high position in society with human respect. Specifically, teaching training is being paid attention to in the comprehensive practising program and focused practical activities (Berseneva, 2015; Egupova, 2020; Phan et al., 2020). The training targets not only the initial education when pedagogical students graduate but also the presentation of an essential career field in society. For example, in the US, the term "teacher professional development" is used instead of "Teacher training" because knowledge and skills learned, in theory, will become obsolete, teachers need to be trained continuously through the performance at their workplaces (Bekbolganova et al., 2015). Especially, in the century of advanced technology and science application in various areas, the teaching position requires not only professional training and skills but also fostering knowledge and ability in Information and Communication Technology usage, knowledge of social issues, updating research results on educational psychology in general as well as modern methods, and new teaching techniques in practical (Glavatskikh, 2010; Kucepal, 2018).

Overview of training activities for high school teachers

International research on training activities for high school teachers

The first thing which needs to be modified is about philosophical issues and different perspectives on teacher training. Those are methodological problems, which form the basis for system design and teacher training (Phan et al., 2020; Karlidag-Dennis et al., 2020). In the study "The formation of professional competence of teachers in fostering and improving qualifications" Belyaeva et al. (2019), mentioned several key issues related to the capacity in training, profession, social knowledge, the foundation of personality, and other career competences following the experience of the US, Russia and Europe country (Marzano et al., 2001).

According to Warren-Piper (1978), argue that: Teaching development is the promotion of a series of systematic activities that meet an individual's standards of interests, wilings, aspirations for their career path, and the future demand of the organization. The author has mainly researched fostering teachers according to the professional development approach. The paper also uses some research on teacher training in the world by foreign authors like (Develay, 1994). French with the work "Peut; On former les Enisgnants", N. I. Bonderup with "Methods of educational activities in high schools", Jacques Nimier with the work "Psychological training teachers". These 
authors emphasized that psychological reinforcement does not satisfy enough in the study process, but in later professional life, teachers must always train themselves (Brener et al., 2003; Amorose \& Anderson-Butcher, 2007).

In these works, the authors have clearly stated the position and importance of teacher training curriculum. Recently, those results still create a theoretical basis for the renewal of teacher training in the direction of moving from a static concept (the initial training for fulfill the teacher role in their performance) to a dynamic concept (the training objective focuses on an open system and a continuous development process from initial training to the probationary period, and in-service training and continuing education at last. Arends et al. (1998), with the study "Learning to teach" has dealt with many teaching and learning troubles. Revolving around the teacher, and educating methods to gravitate towards students, the process requires improvements in professional capacity, which applies specialized skills to teaching. As a consequence, the issue of regular training for teachers is a necessity (McGill et al., 1992; Broadbent \& Laughlin, 2009).

Raja Roy Singh researched teacher development by investigating the role and position of teachers on a theoretical basis proposing measures and contents to develop the teaching staff. According to the author, teachers are not only professionals but also educators, scientists, counsellors, guides, life-long learners, which necessitates them to specialized study and develop researching ability in applied pedagogical science. Authors Hannele Niemi and Ritva Jakku-Sihvonen have detailly and convincingly analyzed important changes in the structure and content of teacher training programs to improve the quality of education in Finland. On the other hand, A.Carin, Craig A.Mertler, Marzano have researched deeply and proposed potential measures to form teaching capacity for teachers. Moreover, Author Marzano (2007) suggested some orientations in the lesson; the instructor must know how to map knowledge, inculcate key points, and promote the cooperation of students. That is the reason why fostering pedagogical competence for teachers has become more and more indispensable. Villegass-Reimers (2003) brought out the discovery of nurturing teachers through a number of models such as: cooperative organization model between schools or small-scale model (schools, classrooms).

Following Andrea Kárpáti in the document Professional development and educater training, the paper provides several recommendations with closely linking teacher professional development programs with in-service training at the workplace. Hence, the improvement direction can be proposed by the evaluation of the teacher's capacity after the course. The advanced training program of coaches and teachers from the European Teacher Training Policy (ENTEP) network has identified that teachers need to be equipped with new competencies. In detail, they should be able to use IT effectively, with high specialization and personal responsibility for career development (Euphropean Commission, 2010). The report of ENTEP for a conference held in Brussels in June 2005 adopted the outline of General Principles of Teacher Qualifications and Competency in Europe, focusing on the following principles: Teachers must prepare a good professional background; Teachers are a dynamic profession with uninterrupted professional development (Euphropean Commission, 2010). Along with this perspective, in the state of Quebec (Canada), some researchers have presented a set of teacher competency standards; proposing the problem of renewing the concept of teacher training; suggesting the design of future programmes (European Union, 2010; Darling-Hammond et al., 2010).

In the Philippines, there are also many models of fortification in different forms: presentations, seminars, professional activities at schools, tutoring, model instruction, online. In the Federal Republic of In Germany, teacher training activities are also carried out through the following methods: participation in compulsory training courses according to the state program, training through the consulting and support system of the state education agency (BUSS), the teacher training network and school internal improvement schedule. Besides, in the UK, the thriving process is conducted through continuous professional development (CPD) through an inter-school network; fostering through intensive courses, seminars, cooperation (Wang et al., 2021; Darling-Hammond, 2016). International research has mentioned a lot of training content with specific requirements. The purpose of these works is to foster professional and scientific knowledge, teaching skills, etc. to develop compulsory teaching competencies for teachers, towards occupancy standards. The authors also affirm the extreme importance of the staff training, with the convinced and detailed analysis in many contents and forms of teacher education strategy. Therefore, those above studies have introduced many methods of fostering for each program, subject, which is suitable for certain characteristics of each national education system associated with the performance process of teachers. Furthermore, those approaches also paid attention to the connection between students and lecturers, among different educational institutions in order to improve the quality of training (Anderson \& Vastag, 2004; Marinescu et al., 2015).

In "Methods and techniques for promotion in high school" by NMIacopepp, or "Self-training to teach" by Patrice Pelpel, MM Rubinstein, PM Phoriboc, NV Cudomina, Ph.M. Gonobolin touched on specific requirements on knowledge, skills, techniques for high school educaters and implementation methods. The methods of fostering teachers that the UK higher education program chose are: theory description; practice in a staging or classroom 
setting; feedback on structural and open-ended performance aspects. These directions have been applied and achieved remarkable results. However, there are not many papers mentioned about the detailed content of fostering teachers, but initially, the researchers have provided a number of methods to stimulate creative thinking of both teachers and students. Thus, that is an orientation for educators to continue investigating for current teacher training (Lai \& Ng, 2011; Wu \& Chang, 2015).

\section{Research in Vietnam on training activities for high school teachers}

In 1961, with the establishment of the Vietnam Institute of Educational Sciences, including the Center for Teacher Researching and Training, there were a number of independent and in-depth investigations. Some typical projects are "Plan for regular pedagogical training" of Dang Vu Hoat, State-level project "Teachers according to the request of educational development" with the participation of many scientists from Hanoi National University of Education, "Training and fostering teachers" (1992) of Le Tran Lam, "Retraining and retraining human resources" (1996) (Research results of Project No. KX) 07-14-1996) from Nguyen Minh Duong. All of these is a group of research topics on general training and fostering teachers from a theoretical perspective. . In 1968, the government promulgated the policy that "every school is a teacher training facility", which reflects the awareness of the importance of education in our country (Nguyen Thi Mai \& Hall, 2017; Sai \& Anh, 2016).

Tran $\mathrm{Ba}$ Hoanh has many research projects on the instructing position and teacher training, relating to the article "Recent innovations in training and fostering for secondary school instructors in some countries", Journal of Information Science Education, No. 77, (2000). In specific, the article "Innovation in teacher training methods" and "On-site training and remote training" covered quite fully the role, content, methods, and ways of fostering teachers in the current period (Tien \& Anh, 2019; Thanh Pham \& Renshaw, 2015). According to Sai \& Anh (2016); Thanh Pham \& Renshaw (2015); Tran (2014); Trinh (2018), the final report of the state-level project "Researching and proposing measures to reform the training and development of high school teachers", the leader - Binh (2013), clearly stated the actual situation of the school's activities such as: Formation, content, objectives of training process; Pointing out the limitations of related issues. From the analysis of the current evidence, the author has proposed measures to fundamentally improve the method of training and fostering teachers.

The final report of the Research Project at the Vietnam Institute of Educational Sciences: "The current situation of fostering teachers in continuing education centers", the subject leader - Hoang et al. (2014), has proposed a number of recommendations to improve the quality of training for teachers with several implemented steps and detailed instruction. The application of professional activities in high schools is an effective form of teacher training that has been confirmed in many research of various authors. Vu \& Kim (2012), specifically mentioned two forms of professional activities: organizing by topics and attending class discussions. Online lessons are determined as a suitable platform for modern society development, which has been confirmed in the research (Nguyen, 2013; Nguyen, 2013). The conclusion of Nguyen et al. (2012), illustrates that nurturing and improving specialized knowledge for teachers through the lesson analyzing model will be more feasible than other traditional forms. These authors believe that teachers' cooperation can share experiences, and help each other improve their pedagogical skills through this structure (Nguyen Thi Mai \& Hall, 2017; Sai \& Anh, 2016; Tien \& Anh, 2019; Thanh Pham \& Renshaw, 2015; Tran, 2014; Trinh, 2018).

Regarding the training methodology, there is a lack of studies referring to works and articles of Nguyen Huu Dung in 1996 at the present. The author has outlined specific directions and confirmed that the reason for each selection is based on many factors such as the learner's level, training areas and learning objectives, as well as the tutor's quality, etc. Additionally, Nguyen Thi Tuyet Trinh, believes that there is a need for focusing on strengthening practice, answering questions for learners. Besides, Pham Duc Bach proposed an effective approach of professional development for teachers through discussions in pedagogical activities, or with Do The Hung, Nguyen Van Hanh, they were concerned about experiential learning methods (2013). The explore in this direction of the those scientists mentioned above discussed the following basic issues:

- Regular teacher training and retraining is highly valued in many countries, not only in pedagogical schools, but also in later professional life that requires teachers to keep re-updating themselves.

- There is a switch from a static concept (the initial training for teachers to fulfill their role in the career path) to a dynamic concept (training should be seen as an open system and a development process continuously from initial objective to the probationary period, then finalizing with in-service training and continuing education).

- The trend of teacher training is shifting from focused development to school-based retraining. 
A number of domestic studies have mainly analyzed the current situation of high school teachers' contingent, determining the content, methods, proposing direction for fostering, and providing potential measures for fundamental innovation in training and improving teacher's performance to catch up with the requirements of general education reform in the modern world (Bennett \& Rohlf, 2007; Frederiksen \& White, 1989).

\section{Findings}

Through an overview of the research problem, the author found that: Teacher training activities and management of those processes for high school teachers have been concerned extremely for a long time in many countries and especially in Vietnam. Teacher training programs and managing those activities are key factors to upgrade the core quality of education. The methodology of teacher training in different countries is diverse, but they all emphasize that educators self-study throughout their life, with the fostering based on schools, and educational management agencies. Moreover, the school environment should create favorable conditions for teachers to enhance their professional development. The research result also reveals that there are just a few works profoundly involved with fostering and managing professional capacity building for teachers, nor having any finding covered the professional development control for each subject or specific discipline. Therefore, studying the management of training activities according to particular specialties is another ideal direction to encourage in the improvement of the course quality at schools and the outcome of educational institutions in general (Cevallos et al., 2020; Guerrero et al., 2021).

\section{Conclusion}

Lecturer training is a principal task to ensure the condition of teaching staff in the current and future school workforce. This study has highlighted some gaps in in-depth research on training activities for high school teachers in Vietnam. In this way, this is the research direction that the author is pursuing.

\section{References}

Amorose, A. J., \& Anderson-Butcher, D. (2007). Autonomy-supportive coaching and self-determined motivation in high school and college athletes: A test of self-determination theory. Psychology of sport and exercise, 8(5), 654670. https://doi.org/10.1016/j.psychsport.2006.11.003

Anderson, R. D., \& Vastag, G. (2004). Causal modeling alternatives in operations research: Overview and application. European Journal of Operational Research,156(1), 92-109. https://doi.org/10.1016/S03772217(02)00904-9

Arends, R. I., Tannenbaum, M. D., \& Winitzky, N. E. (1998). Exploring teaching. McGraw-Hill.

Bekbolganova, A. K., Akhmetova, G., \& Mukhaeva, A. (2015). Applied tasks and principles of building their system. Eurasian Union of Scientists (ESU). Pedagogical sciences, 10(19), 15-17.

Belyaeva, I. G., Samorodova, E. A., Voron, O. V., \& Zakirova, E. S. (2019). Analysis of innovative methods' effectiveness in teaching foreign languages for special purposes used for the formation of future specialists' professional competencies. Education sciences, 9(3), 171.

Bennett, P. C., \& Rohlf, V. I. (2007). Owner-companion dog interactions: Relationships between demographic variables, potentially problematic behaviours, training engagement and shared activities. Applied Animal Behaviour Science, 102(1-2), 65-84. https://doi.org/10.1016/j.applanim.2006.03.009

Berseneva, O. V. (2015). Competence-oriented tasks as a means of improving the research competencies of future mathematics teachers. Internet Journal "World of Science", 3, 1-17.

Binh, N. T. (2013). Improve state management of capital construction investment from the state budget in Vietnam's transport industry.

Brener, N. D., McManus, T., Galuska, D. A., Lowry, R., \& Wechsler, H. (2003). Reliability and validity of selfreported height and weight among high school students. Journal of adolescent health, 32(4), 281-287. https://doi.org/10.1016/S1054-139X(02)00708-5

Broadbent, J., \& Laughlin, R. (2009). Performance management systems: A conceptual model. Management Accounting Research, 20(4), 283-295. https://doi.org/10.1016/j.mar.2009.07.004

Cevallos, M. A. M., Cedeño, Ángela M. C., \& Gámes, M. R. (2020). Maker movement: strategy for the construction of knowledge in high school students. International Research Journal of Management, IT and Social Sciences, 7(4), 1-8. https://doi.org/10.21744/irjmis.v7n4.935

Darling-Hammond, L. (2016). Global education reform: How privatization and public investment influence education outcomes. 
Darling-Hammond, L., Newton, X., \& Wei, R. C. (2010). Evaluating teacher education outcomes: A study of the Stanford Teacher Education Programme. Journal of Education for Teaching, 36(4), 369-388.

Develay, M. (1994). Peut-on former les enseignants?. Éditions ESF,.

Egupova, M. V. (2020). Practice-Oriented Tasks for Schools: Methodology for Future Mathematics Teachers. Математика и информатика, 63(6), 590-600.

Euphropean Commission. (2010). Te hers' rofession 1 evelopment Europe in International Comparison.

European Union. (2010). Teahers' Professional Development: Europe in International Comparison, Belgium.

Frederiksen, J. R., \& White, B. Y. (1989). An approach to training based upon principled task decomposition. Acta psychologica, 7l(1-3), 89-146. https://doi.org/10.1016/0001-6918(89)90006-1

Glavatskikh, I. M. (2010). Professionality of direct mathematical training of future engineer-teacher. Kyiv: National Pedagogical University of M.P. Drahomanov.

Guerrero, J. A. A., Moreira, J. A. M., Zambrano, M. J. Z., Rivas, F. E. C., \& Pilligua, M. L. B. (2021). Project-based learning and its contribution in virtual education. International Research Journal of Management, IT and Social Sciences, 9(1), 10-18. https://doi.org/10.21744/irjmis.v9n1.1973

Hoang, M. H., Ha, N. C., Tam, L. T., Anh, H. T. L., Thu, N. T. H., \& Hong, D. D. (2014). Extraction of squalene as value-added product from the residual biomass of Schizochytrium mangrovei PQ6 during biodiesel producing process. Journal of bioscience and bioengineering, 118(6), 632-639.

Karlidag-Dennis, E., Hazenberg, R., \& Dinh, A. T. (2020). Is education for all? The experiences of ethnic minority students and teachers in North-western Vietnam engaging with social entrepreneurship. International Journal of Educational Development, 77, 102224.

Kucepal, S. (2018). Stem/Steam/Stream-education is a new trend in the Ukrainian educational discourse. Education Landscapes, 1, 11-14.

Lai, Y. C., \& Ng, E. M. (2011). Using wikis to develop student teachers' learning, teaching, and assessment capabilities. The Internet and Higher Education, 14(1), 15-26. https://doi.org/10.1016/j.iheduc.2010.06.001

Marinescu, R., Seceleanu, C., Le Guen, H., \& Pettersson, P. (2015). A research overview of tool-supported modelbased testing of requirements-based designs. Advances in Computers, 98, 89-140. https://doi.org/10.1016/bs.adcom.2015.03.003

Marzano, R. J. (2007). The art and science of teaching: A comprehensive framework for effective instruction. Ascd.

Marzano, R. J., Pickering, D., \& Pollock, J. E. (2001). Classroom instruction that works: Research-based strategies for increasing student achievement. Ascd.

McGill, M. E., Slocum Jr, J. W., \& Lei, D. (1992). Management practices in learning organizations. Organizational dynamics, 21(1), 5-17. https://doi.org/10.1016/0090-2616(92)90082-X

Nguyen Thi Mai, H., \& Hall, C. (2017). Changing views of teachers and teaching in Vietnam. Teaching Education, 28(3), 244-256.

Nguyen, H. M., Cavoli, T., \& Wilson, J. K. (2012). The determinants of inflation in Vietnam, 2001-09. ASEAN Economic Bulletin, 1-14.

Nguyen, M. T. (2013, June). Minimizing energy consumption in random walk routing for wireless sensor networks utilizing compressed sensing. In 2013 8th International Conference on System of Systems Engineering (pp. $297-$ 301). IEEE.

Phan, T. T. T., Ta, N. T., Duong, V. A. P., \& Hoang, A. D. (2020). Dataset of Vietnamese teachers' habits and motivation behind continuous professional development programs participation. Data in Brief, 33, 106525.

Sai, H. C., \& Anh, T. (2016). Solutions for improving students' competences under alumni's perspectives at Vietnam National University Hanoi, Vietnam [J]. The International Journal of Humanities \& Social Studies, 4(5), 300306.

Thanh Pham, T. H., \& Renshaw, P. (2015). Formative assessment in Confucian heritage culture classrooms: activity theory analysis of tensions, contradictions and hybrid practices. Assessment \& Evaluation in Higher Education, 40(1), 45-59.

Tien, N. H., \& Anh, D. B. H. (2019). The Role of International Trade Policy in Boosting Economic Growth of Vietnam.". International journal of commerce and Management Research, 5(3), 107-112.

Tran, K. (2014). Developing tertiary education in Vietnam [J]. Journal of Vietnamese Social Science, 10(83), 54-62.

Trinh, A. N. (2018). Local Insights from the Vietnamese Education System: the impacts of imperialism, colonialism, and the neo-liberalism of globalization. International Education Journal: Comparative Perspectives, 17(3), 6779.

Villegas-Reimers, E. (2003). Teacher professional development: an international review of the literature. Paris: International Institute for Educational Planning. 
Vu, V. H., \& Kim, K. (2012). Improvement of cellulase activity using error-prone rolling circle amplification and site-directed mutagenesis. Journal of microbiology and biotechnology, 22(5), 607-613.

Wang, T., Ramdeo, J., \& McLaughlin, C. (2021). Experiencing and experimenting: An exploration of teacher agency in an international collaborative teacher professional development programme using experiential learning. Teaching and Teacher Education, 104, 103389.

Warren-Piper, D. (1978). Flexibility with control: an example of classroom contact and some other attempts to increase effectiveness. The efficiency and effectiveness of teaching in Higher Education. University of London Teaching Methods Unit.*** The Governmental decision regarding the organization of undergraduate studies, no, 88 .

Wu, S. C. A., \& Chang, Y. L. A. (2015). Advancing kindergarten teachers' knowledge and capabilities of differentiated instruction associated with implementation of thematic integrated curriculum. Procedia-Social and Behavioral Sciences, 177, 246-250. https://doi.org/10.1016/j.sbspro.2015.02.404 